\title{
Tax Aversion, Laffer Curve, and the Self-financing of Tax Cuts
}

\author{
Gerasimos T. Soldatos ${ }^{1}$ \\ ${ }^{1}$ American University of Athens, Department of Business Administration, Athens, Greece \\ Correspondence: Gerasimos T. Soldatos, Pindarou 43, 56224 Thessaloniki, Greece
}

Received: February 9, 2015

Accepted: February 26, 2015

Available online: March 12, 2015

doi:10.11114/aef.v2i2.714

URL: http://dx.doi.org/10.11114/aef.v2i2.714

\begin{abstract}
High taxation is found to lead not to less labor supply but to more tax evasion and/or black labor. Investigating next what this implies for the course of the tax revenue and subsequently for the shape of the Laffer curve, this curve is found to change with the tax induced change of taxpayer preferences over tax compliance and tax aversion. Hence, the relevant Laffer curve when contemplating tax cuts should be the one after the last tax increase and cannot thereby be fully self-financed.
\end{abstract}

Keywords: Laffer curve, Tax evasion/black labor, Self-financing tax cuts

JEL classifications: E62, H26, J22

\section{Introduction}

One of the latest addition to the literature advocating an upward sloping Laffer curve all the way up to the tax rate of $100 \%$ is Usher's (2013) paper, in which tax evasion enters into the discussion indirectly as a source of bias when estimating the peak of this curve. This note, by introducing tax evasion into the original theoretical modeling of the "ever-increasing" Laffer curve by Malcomson (1986) and Denicolò (1988), presents a direct link between the two concepts. This is done in the first part of the next section, complementing thus Usher's presentation of the matter. Yet, a full treatment of the subject should focus on the implied link between the Laffer curve and underground economy, too. This task is undertaken in the second part of the following section through a deterministic Lotka-Volterra system rather than via Busato and Chiarini's (2012) dynamic general equilibrium approach. Tax revenue is found to be more sensitive to changes in tax aversion (tax evasion and/or tax-induced black labor) behavior relative to changes in tax aversion attitudes in response to tax cuts. Consequently, a disturbance of the steady state by tax authorities would incite increasing instability.

Incentives matter and are found indeed to alter the way taxpayers assess the tax rate scale, making in turn the shape of the Laffer curve susceptible to the unit of measurement of the tax rate axis when the curve is drawn as a frequency plot. Section 3 concludes this paper stressing this nexus between Laffer curve and the incentives of the taxpayers beyond their resource constraints. It is this line of inquiry, having produced this paper and its main result crystallized in its title. The curve should be contemplated analytically and policy-wise under the dynamic-scoring mentality underlying the question: "by how much a tax cut is self-financing if we take incentive feedback effects into account" (Trabandt and Uhlig 2011, p.1) given that 32\% of a labor tax cut in the US and 54\% in EU-14 are self-financing (Trabandt and Uhlig 2011, p.1). The answer to this question provided here within the particular theoretical context employed below is that only partly a tax cut can be self-financing. For example, it is noteworthy that increases in corporate tax rates are found empirically by Ljungqvist and Smolyansky (2014) to lead to significant reductions in employment and income, with little evidence that corporate tax cuts boost economic activity.

\section{Analysis}

\subsection{The Standard Modeling Extended}

According to Malcomson (1986), there are $N$ identical individuals, each maximizing the Stone-Geary utility function:

$$
U=\ln (\bar{L}-L)+b \ln (C-\bar{C})
$$

subject to the constraint that: $C=(1-\tau) L$, where $\bar{L}$ and $L$ are labor endowment and supply, respectively, $\bar{C}$ is "survival" consumption, $C$ is consumption above $\bar{C}, \tau$ is the tax rate, and $b$ is a constant. The resulting expression for $L$ is: 


$$
L^{*}=\frac{b}{1+b}+\frac{\bar{C}}{(1+b)(1-\tau)}
$$

with $d L^{*} / d \tau>0$, implying thereby the upward sloping Laffer curve: $T=\tau N L^{*}(\tau)$, up to the point $\tau=1$, where it presents discontinuity. Denicolò (1988) interprets this discontinuity as a sudden fall in labor supply once individuals can no longer survive. Now, let the above constraint become: $C=p(1-\tau) L+(1-p) L=>C=(1-p \tau) L$, where $p$ is the probability of the detection of tax evasion. (2) becomes:

$$
L^{* *}=\frac{b}{1+b}+\frac{\bar{C}}{(1+b)(1-p \tau)}
$$

with Laffer curve: $T=\tau N L^{* *}(p, \tau)$. According to (3), labor supply at $C=\bar{C}$ does not fall to zero and no discontinuity emerges at $\tau=1$, simply because of the possibility of surviving through tax evasion. And, certainly, $\tau N L^{*}(\tau)>\tau N L^{* *}(p, \tau)$, because $L^{*}(\tau)>L^{* *}(p, \tau)<=>p<1$. Denicolò (1998) also points out that discontinuity cannot be given rise under (2) anyway, since setting a $\tau=1$ in the constraint $\bar{C}=(1-\tau) \bar{L}=>\tau=1-(\bar{C} / \bar{L})$, one obtains that $0=-(\bar{C} / \bar{L})$, which would hold only if $\bar{C}=0$. This appears to be the case in the presence of tax evasion as well; a $C=\bar{C}=0$ means that all chances to make ends meet have been exhausted. Actually, the optimization problem behind (2) is not well defined for $\tau \geq 1-(\bar{C} / \bar{L})$ and the value $\tau=1$ is thereby inadmissible. But, the tax rate may do take on such a value in connection with the problem behind (3), because the constraint $\bar{C}=(1-p \tau) \bar{L}=>$ $\tau=(\bar{L}-\bar{C}) / p \bar{L}$, and a $\tau=1$ is possible when $\bar{C} / \bar{L}=(1-p) / p$.

These results to hold need the changes in $\tau$ to affect $L$, and according to labor economics, little only appears to be the evidence supporting such a link (see e.g. Slemrod 2000). One reason for this conclusion is that the data used are after-tax-invasion data as follows: Let from (2) and (3)

$$
\epsilon^{*}=\frac{d L^{*}}{d \tau} \frac{\tau}{L^{*}}=\frac{\bar{C}}{(1+b)(1-\tau)^{2}} \frac{[b(1-\tau)+\bar{C}]}{\tau(1+b)(1-\tau)}
$$

and

$$
\epsilon^{* *}=\frac{d L^{* *}}{d \tau} \frac{\tau}{L^{*}}=\frac{p \bar{C}}{(1+b)(1-p \tau)^{2}} \frac{[b(1-p \tau)+\bar{C}]}{\tau(1+b)(1-p \tau)^{\prime}}
$$

respectively. Their comparison amounts after some operations to the comparison of the terms: $[b(1-p \tau)(1-\tau)(1-$ $\left.p)\left(p \tau^{2}-1\right)\right]$ and $\left\{\bar{C}\left[(1-p \tau)^{3}-p(1-\tau)^{3}\right]\right\}$. The first in order term is clearly negative given that both $p$ and $\tau$ are both decimals. To see the sign of the second term suffices to compare $(1-p \tau)$ with $(1-\tau)$ given that if the former exceeds the latter so will their cubes and much more so when $(1-\tau)^{3}$ is multiplied with the decimal $p$. Indeed, $1-p \tau>1-\tau<=>p<1$, which is true. Therefore, $\epsilon^{* *}<\epsilon^{*}$ : High tax rates do not lead to less work but to shift income out of taxable form. Nowadays, the Laffer curve is considered to be empirically an illusionary concept, because it is detached from taxpayer-incentives considerations as they are prompted by the reality of tax evasion. If not anything else, a worker may be inquiring about a second, twilight job, and a businessman may be deliberating ways to go informal just when the government will be thinking that is improving social welfare! Methodologically, this is one more example of the thesis that what matters cognitively, is the empirical implications of a theoretical construct and not the empirical content of the construct per se. In what follows, a formal modeling of these conclusions is attempted.

\subsection{A Generalized Laffer Curve}

Let the percentage of $\bar{L}$ having produced the unreported income and/or channeled underground be $z, 0<z<1$, so that $\bar{L}=z L+(1-z) L$. That is, unofficially, there is always full employment, and part of the income unreported to the tax authorities may be the result of tax evasion or underground activities or both. Let next $\varphi$ and $\pi$ be the rates of change of $t=T / \bar{T}$ and $l=z L / \overline{z L}$, respectively, given $N$. The quantities $\bar{T}$ and $\overline{z L}$ are the highest values $T$ and $z L$ can reach. Let moreover $\beta$ represent the harmful effect the growth of $l$ has on $t$ and $\delta$ represent the negative influence of a declining $T$ and increasing $(1-t)$ on $l$. These parameters need not be equal, only positive as follows:

$$
\begin{gathered}
\frac{d t}{d \tau}=\varphi t[1-(t+\beta l)] \\
\frac{d l}{d \tau}=\pi l\{1-[l+\delta(1-t)]\}
\end{gathered}
$$


These two differential equations form a competitive Lotka-Volterra system (Bomze 1995) where the quantities $t$ and $l$ are bounded between 0 and 1 at all times. Equilibrium occurs in the model when neither of these quantities is changing, i.e. when both of the derivatives are equal to 0 , which is the case when:

$$
t+\beta l=1 \quad \text { and } \quad l+\delta(1-t)=1
$$

with unique solutions:

$$
\hat{l}=\frac{1}{1+\beta \delta} \text { and } \hat{t}=\frac{1-\beta(1-\delta)}{1+\beta \delta}
$$

That is, all depends on the values of the parameters $\beta$ and $\delta$, with (i) $\hat{t}$ being equal to $\hat{l}[1-\beta(1-\delta)]$ and hence, with $d \hat{t} / d \hat{l}=1-\beta(1-\delta)<0=>1-\delta>1 / \beta$, and (ii) $\hat{l}=(1-\hat{t}) / \beta$ and hence, with $d \hat{l} / d(1-\hat{t})=1 / \beta$ : Tax revenue is more sensitive to changes in tax evasion and/or black labor behavior relative to changes in tax evasion and/or black labor attitudes in response to tax cuts. Consequently, only partly such cuts can prove to be self-financing and a disturbance of the steady state by tax authorities would destabilize the economy permanently. Indeed, evaluating the Jacobian $J$ at the steady state of $(\hat{l}, \hat{t})$ we get:

$$
J(\hat{l}, \hat{t})=\frac{1}{1+\beta \delta}\left[\begin{array}{cc}
\varphi[\beta(2-\delta)-1] & -\varphi \beta[1-\beta(1-\delta)] \\
\pi \delta & \pi[\beta \delta(1-\delta)-(1+\delta)]
\end{array}\right]
$$

with a complicated cubic characteristic equation in $\delta$, which connotes increasing instability once equilibrium is disturbed, since no limit cycle can exist within the context of any two-dimensional model of this type (Hirsch 1990). Intuitively, those who give in to tax evasion and/or underground activities have been taking some pain before deciding to do so, and once they do, many of them distrust policy incentives to leave this "safety net" despite any risks of getting caught by the authorities. Taxpayer incentives before and after tax aversion are not the same.

This is perhaps the reason the shape of the Laffer curve as a frequency plot in the $\tau-t$ space depends on the unit of measurement of the $\tau$-axis as in Figure 1 where $\Lambda_{1}$ is the Laffer curve before tax aversion and $\Lambda_{2}$ is one such curve after tax aversion. Within the context of $\Lambda_{1}$, tax aversion appears to postpone the peak of the curve. But, in reality, tax aversion changes the unit of measurement of the $\tau$-axis so as to be compatible with the incentives that induced aversion. People do not see the tax rates

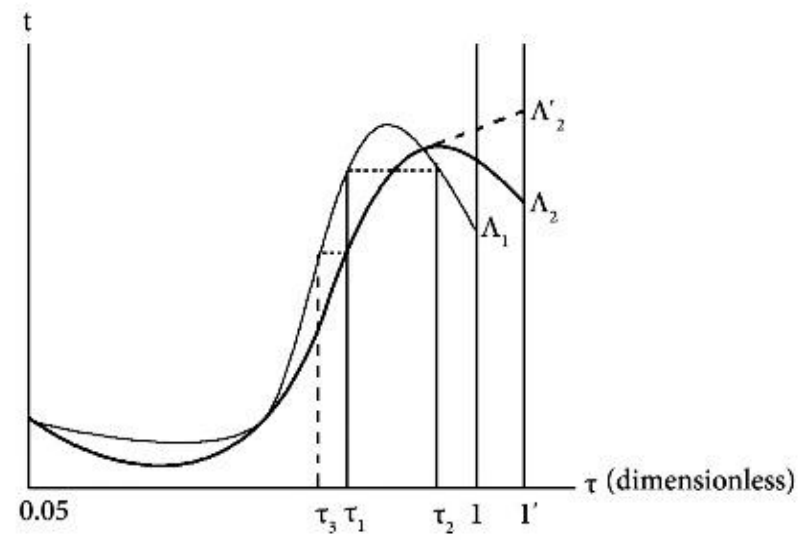

Figure 1. Laffer curve as A Frequency Plot

with the same eye as before tax aversion. Within the framework of $\Lambda_{1}$, a tax cut from $80 \%$ to $65 \%$ is expected to yield the same tax revenue, but it actually yields the revenue corresponding to $60 \%$, because simply the relevant Laffer curve is $\Lambda_{2}$. The difference in the measurement unit reflects the difference in incentives, and it is up to this unit if the curve exhibits a peak at all; $\Lambda_{2}^{\prime}$ instead of $\Lambda_{2}$ might had been the case. Moreover, it is for this reason that "an inverse relationship between tax rates and tax revenues may exist at low levels of the tax rate" (Waud 1985) as Figure 1 illustrates as well.

\section{Concluding Remarks}

What is for sure is that "in a simple Mirrleesian model of income taxation...the second-best frontier which incorporates incentive constraints relates to the first-best frontier which takes only resource constraints into account...[and] the second-best frontier can be interpreted as a Laffer-curve" (Bierbrauer and Boyer 2010, p. 1). Incentives influence the shape of this curve, indeed, which is a hypothesis that should be documented empirically and investigated further 
through alternative theoretical constructs. And, to the extent things have more or less the way described herein, when tax cuts are contemplated the point of reference should not be the position on the pre-tax Laffer curve. The policymaker should also bear in mind that the same incentives, which herein contain the influence of tax cuts, have externalities: "tax evaders protect each other, because they tie down limited enforcement capacity. Thus... tax rate cuts...can lead to increased revenues through spillovers...imply[ing] increasing effective taxes" (Papp and Takáts 2008, p. 1).

From the viewpoint of the habit-formation approach, the decision to engage in tax aversion might be taken to be the outcome of agents facing shocks to their abilities to generate labor income. Labor income is publicly observed, but abilities and labor supply are private information and since, habit formation connects present and future self-selection, the complementarity between habits and consumption, makes self-selection easier in the future if the worker consumes a lot in the present, engaging as a result in tax aversion, (Koehne and Kuhn 2015). This habit effect calls for subsidies to labor supply rather than for tax cuts.

An exception to the persistence of the decision for tax aversion appears to the case according to which this decision is made aiming at earning the money needed to pay to the tax authority some fixed price for the reduction of the marginal tax rate; it is the case of the so called "tax buyouts", (Goerke 2015). Also, judging from the work of Strulik (2010) about anticipated tax reforms and temporary tax cuts, tax aversion might prove to be temporary in this case, too. Another exception is that the taxation inducing tax aversion is certainly distortionary, and tax reduction would reduce tax burden considerably, making a decision to return back to formality easier. Finally, the policymaker might wish to deliberate about the possibility that "tax revenue may be greater under tax evasion than without evasion if evasive ability allows government to act as a price-discriminating monopolist" (Palda 1998, p. 1118). The exploitation of such a possibility and persuasion rather than punishing means, the tax authority should be implementing to address the problem of tax compliance given that punishment is a lump-sum loss and does not modify incentives.

Acknowledgements

I am grateful to two anonymous reviewers for their constructive criticism. Any remaining errors and omissions are my own.

\section{References}

Bierbrauer, F. J., \& Boyer, P. (2010). The Pareto-frontier in a simple Mirrleesian model of income taxation. MPI Collective Goods Preprint No. 2010/16. Retrieved from http://www.coll.mpg.de/pdf_dat/2010_16online.pdf

Bomze, I. (1995). Lotka-Volterra equation and replicator dynamics: New issues in classification. Biological Cybernetics, 72, 447-453. http://dx.doi.org/10.1007/BF00201420

Busato, F., \& Chiarini, B. (2012). Steady state Laffer curve with the underground economy. Government of the Italian Republic, Ministry of Economy and Finance, Department of the Treasury Working Paper No.8. Retrieved from http://www.dt.tesoro.it/export/sites/sitodt/modules/documenti_en/analisi_progammazione/working_papers/WP_N_ 8-2012.pdf

Denicolò, V. (1988). Some analytics of the Laffer curve: A comment. Journal of Public Economics, 35, 129-130. http://dx.doi.org/10.1016/0047-2727(88)90065-5

Goerke, L. (2015). Income tax buyouts and income tax evasion. International Tax and Public Finance, 22, 120-143. http://dx.doi.org/10.1007/s10797-013-9302-z

Hirsch, M.W. (1990). Systems of differential equations those are competitive or cooperative. IV: Structural stability in three-dimensional systems. SIAM Journal on Mathematical Analysis, 21(5), 1225-1234. http://dx.doi.org/10.1137/0521067

Koehne, S., \& Kuhn, M. (2015). Optimal taxation in a habit formation economy. Journal of Public Economics, 122, 32-39. http://dx.doi.org/10.1016/j.jpubeco.2014.12.007

Ljungqvist, A., \& Smolyansky, M. (2014). To cut or not to cut? On the impact of corporate taxes on employment and income. NBER Working Paper No 20753. Retrieved from http://www.nber.org/papers/w20753.pdf

Malcomson, J. M. (1986). Some analytics of the Laffer curve. Journal of Public Economics, 29, 263-279. http://dx.doi.org/10.1016/0047-2727(86)90029-0

Palda, F. (1998). Evasive ability and the efficiency cost of the underground economy. Canadian Journal of Economics/Revue Canadienne d'Economique, 31(5), 1118-1138. http://dx.doi.org/10.2307/136462

Papp, T. K., \& Takáts, E. (2008). Tax rate cuts and tax compliance - The Laffer curve revisited. IMF Working Papers 08/07. Retrieved from http://www.imf.org/external/pubs/ft/wp/2008/wp0807.pdf 
Strulik, H. (2010). Anticipated tax reforms and temporary tax cuts: A general equilibrium analysis. Journal of Economic Dynamics and Control, 34(10), 2141-2158. http://dx.doi.org/10.1016/j.jedc.2010.05.018

Trabandt, M., \& Uhlig, H. (2011). How far are we from the slippery slope? The Laffer curve revisited. MFI Working Paper No. 2009-005.

https://bfi.uchicago.edu/sites/default/files/file_uploads/trabandt_uhlig_laffer_vers25_distrib.pdf

Usher, D. (2013). Two sources of bias in estimating the peak of the Laffer curve. Queen's Economics Department Working Paper No. 1320. Retrieved from http://qed.econ.queensu.ca/working_papers/papers/qed_wp_1320.pdf

Waud, R. N. (1985). Tax aversion, deficits and the tax rate-tax revenue relationship. NBER Working Paper. http://www.nber.org/papers/w1533.pdf

\section{$(\mathrm{cc})$ EY}

This work is licensed under a Creative Commons Attribution 3.0 License. 